\title{
Purchasing unpackaged food products
}

\section{An empirical analysis of personal norms and contextual barriers}

\author{
Gesa Henriette Marken ${ }^{1}$ · Jacob Hörisch²
}

Published online: 12 March 2020

(c) The Author(s) 2020

\begin{abstract}
The food industry causes substantial environmental pressure through generating an increasing amount of plastic waste. This research deals with stores which address this issue, by offering unpackaged food products. As such concepts depend on the support of consumers, a quantitative survey among consumers is conducted. Building on norm activation theory, this paper investigates which individual factors support packaging free purchasing and what barriers hinder consumers to purchase unpackaged food products. Additionally, it is tested whether the perception of barriers towards purchasing unpackaged food products mediates the influence of pro-environmental personal norms on purchasing unpackaged food products. The main barriers identified include a lack of awareness of unpackaged food offerings as well as the restricted range of available unpackaged products. Additionally, the results show that pro-environmental personal norms foster purchasing of unpackaged food. However, this influence is not mediated by the perception of barriers towards purchasing unpackaged food products. Based on these findings, possible interventions are identified, such as in-store marketing, which increase the awareness about unpackaged food offerings, or educational campaigns, which sensitize consumers for the consequences of plastic waste.
\end{abstract}

Keywords Environmental behavior · Consumption · Unpackaged products · Waste · Food · Personal norms · Purchasing · Mediation

Jacob Hörisch

hoerisch@leuphana.de
Institute for Ecological Economy Research, Potsdamer Str. 105, 10785 Berlin, Germany

2 Centre for Sustainability Management, Leuphana University of Lüneburg, Universitätsallee 1, 21335 Lüneburg, Germany 


\section{Der Einkauf unverpackter Lebensmittel}

Eine empirische Analyse individueller Einstellungen und kontextueller Barrieren

\section{Zusammenfassung}

Durch die Verursachung von Plastik-Müll trägt die Lebensmittel-Industrie verstärkt zu Umweltverschmutzung bei. Der vorliegende Artikel untersucht sogenannte „Unverpackt-Läden“, die sich dieses Problems annehmen, indem sie verpackungsfreie Lebensmittel anbieten. Da derartige Konzepte auf den Zuspruch von Konsument/innen angewiesen sind, wurde eine quantitative Kundenbefragung durchgeführt. Aufbauend auf der Norm-Activation-Theorie analysiert dieser Artikel, welche individuellen Faktoren den Kauf von unverpackten Lebensmitteln unterstützen und welche Barrieren Konsument/innen daran hindern unverpackte Lebensmittel zu erwerben. Zudem wird getestet, ob der Einfluss umweltfreundlicher individueller Normen auf das Einkaufsverhalten durch wahrgenommene Barrieren mediiert wird.

Als wichtigste Barrieren gegenüber dem Einkauf von unverpackten Lebensmitteln werden eine mangelnde Bekanntheit von entsprechenden Angeboten sowie die begrenzte Auswahl verfügbarer unverpackter Produkte herausgearbeitet. Die Ergebnisse zeigen darüber hinaus, dass sich umweltfreundliche, individuelle Einstellungen positiv auf den Kauf verpackungsfreier Lebensmittel auswirken. Dieser Einfluss wird jedoch nicht durch die Wahrnehmung von Barrieren mediiert. Auf Basis der Ergebnisse werden mögliche Interventionen vorgeschlagen. Diese umfassen z.B. In-Store-Marketing, um die Bekanntheit des Angebots unverpackter Lebensmittel zu erhöhen oder Bildungskampagnen, die Konsument/innen für die Bedeutung von Plastik-Müll sensibilisieren.

\section{Introduction}

Solid waste generation is increasing worldwide and poses a major challenge to sustainable development (King et al. 2006; Halkos and Petrou 2018). 1.47 billion tons of municipal solid waste are generated annually, which accounts for $436 \mathrm{~kg}$ per individual per year. Globally, only $15 \%$ of collected waste is recycled, while the remaining $85 \%$ are stored in landfills (Zaman 2016). This puts an immense pressure on the environment and can evoke social, political and economic conflicts concerning the placement of such facilities (Marsh and Bugusu 2007). A major contributor to the waste issue is the food industry (Smits Sandano 2016). Multiple authors highlight, that the food industry is of specific importance, as it not only creates food waste but also packaging waste, including environmentally harmful plastic packaging (Marsh and Bugusu 2007; Williams et al. 2012; Smits Sandano 2016). Plastic materials are preferably being used for food packaging due to their characteristics of having low density, good mechanical properties and being available at low cost (Andrady 2015). These favorable characteristics lead to an increase of plastic production of $620 \%$ between 1975 and 2012 (Jambeck et al. 2015). Analogously, the amount of plastic waste increased substantially, posing a severe threat to the environment (Andrady 2015). Due to its high durability, the abundance of plastic waste leads to the persistence of synthetic polymers in ecosystems which cause harm to organisms and humans (Jambeck et al. 2015). Particularly the issue of plastic waste in oceans is receiving growing attention, as plastic accounts for more than $80 \%$ of all waste accumulated in the oceans (Mühlthaler and Rademacher 2017) and nearly half of all marine litter on
European beaches is made of single-use plastics (European Commission 2018).

With regard to reducing waste in food-packaging, supermarkets are regarded as gatekeepers that "hold the power to induce positive change at both consumer and supplier side" (Beitzen-Heineke et al. 2017, p. 1528). By eliminating all disposable, single-use plastic packaging of food products, packaging free grocery stores respond to the increasing consumer awareness towards social and environmental externalities of food retailing (Beitzen-Heineke et al. 2017). Packaging free stores pursue a preventative approach which implies that waste is eliminated before it is created (Smits Sandano 2016).

However, the responsibility of reducing packaging waste and its pressure on the natural environment is not confined to businesses (cf. Mainieri et al. 1997). For the expansion of packaging free stores, behavioral change of consumers is required. Thøgersen (1999) even claims that buying decisions are some of the most important consumer decisions concerning the environment. Still, purchasing of unpackaged products requires high levels of consumer's effort, time and capability to plan ahead, as reusable containers must be carried which might compromise the convenience of the shopping experience (Beitzen-Heineke et al. 2017; Kröger et al. 2017; Zeiss 2018). In order to increase packaging free purchasing, it is fundamental to understand ...

\section{... which individual factors support packaging free purchasing and ... \\ ... what barriers hinder consumers to purchase un- packaged food products.}

To address these research questions, this article draws on earlier work on the influence of pro-environmental personal 
norms and contextual barriers on pro-environmental behavior. In so doing, it empirically analyses and compares consumers of packaging free goods with conventional consumers, drawing on a quantitative survey conducted in Germany.

The remainder of the paper is structured as follows. The next section outlines the current state of research and formulates according hypotheses. Subsequently, the methods and the statistical analysis are explained. Sect. 4 presents the descriptive results concerning the most important barriers identified as well as the inferential statistics on the hypotheses testing. Last, the results are discussed and conclusions are drawn with an emphasis on identifying potential interventions to stimulate purchasing of unpackaged food.

\section{Literature review and development of hypotheses}

The need for a transition of the food industry towards a circular economy model has been increasingly recognized in the academic discourse (e.g. Jurgilevich et al. 2016). Previous research indicated environmental and social benefits from reduced packaging in the food retail industry (Sjölund 2016). The increased demand for more sustainable practices in the food industry and the concern about plastic waste evoked the emergence of packaging free stores (BeitzenHeineke et al. 2017; Goldkorn et al. 2017). Based on Bartl (2014) packaging free can be defined as the "total or almost total avoidance of waste by excessive waste prevention and re-use". ${ }^{1}$ Packaging free stores seek to implement this concept in food retail on all levels (Goldkorn et al. 2017). Such stores differ substantially from conventional supermarkets and come along with changes to the overall shopping experience for consumers, who bring their own containers and fill them with the products in the store (BeitzenHeineke et al. 2017; Kröger et al. 2018). Currently, packaging free stores are still a niche market phenomenon, but are identified to bear a huge potential for creating positive environmental impact (Smits Sandano 2016; Kröger et al. 2017). However, the concept requires substantial behavioral change by consumers. Therefore, the question arises what factors encourage this specific form of pro-environmental behavior (i.e. packaging free purchasing) among consumers and which barriers need to be overcome to encourage con-

\footnotetext{
1 Alternatively to the term packaging free, literature also refers to the concepts of zero packaging retail, zero waste stores or no packagingstores (Smits Sandano 2016; Beitzen-Heineke et al. 2017). As such stores still produce some packaging waste in form of paper, carton and plastic foil due to practicality in the delivery process and due to transportation regulations, this paper will refer to these stores as packaging free stores in the sense brought forward by Bartl (2014), i.e. no (plastic) primary packaging of products is used.
}

sumers to purchase unpackaged food products. Yet, there is a lack of research on the barriers of implementing the zero waste concept from a consumer perspective, although consumers are one of the essential stakeholders when developing a packaging free food industry.

This research gap will be addressed in this article building on "norm activation theory" (Schwartz 1977). Norm activation theory assumes that behavior is dependent on an individual's feeling of personal obligation to perform a certain action which is triggered when personal norms are activated. The term personal norm is defined as "the selfexpectations for specific action in particular situations that are constructed by the individual" (Schwartz 1977, p. 227). As further empirical studies prove the relevance of personal norms for environmental behavior (e.g. Harland et al. 1999; Moser 2015) and packaging choice decision in particular (Thøgersen 1999), this paper argues that personal norms are an important predictor of purchasing unpackaged food products. Indeed, Thøgersen (1999) found that moral norms can help to explain packaging choice decisions. He investigated the propensity of Danish consumers to avoid excessive packaging of groceries and tested the predictive power of personal norms and perceived costs on two selfreported measures of purchasing behavior. The data was collected through a telephone survey and analyzed based on structural equation modeling. The results provide indication that moral reasoning is a determinant of environmentfriendlier buying behavior. In fact, Thøgersen (1999) found that personal norms serve as a strong predictor of choosing environment-friendlier packaging while perceived costs do not significantly influence packaging choice decisions. Based on these insights provided by Thøgersen (1999) and earlier findings on the influence of personal norms on proenvironmental behavior in general, it can be expected that pro-environmental personal norms are positively related to purchasing unpackaged food products. Hence hypothesis 1 is formulated as follows.

H1: Consumers with higher levels of pro-environmental personal norms are more likely to purchase unpackaged food products.

Besides the influence of personal norms, research on proenvironmental behavior has emphasized the importance of contextual conditions (e.g. Gardner and Stern 1996; Stern 2000; Jacobs et al. 2018). Still, the influence of these contextual conditions differs between specific research contexts, i.e. not all findings concerning contextual barriers in specific contexts of pro-environmental behavior are transferable to further contexts (Gardner and Stern 1996; Stern 2000). Previous research has already explored potential contextual factors which might act as barriers towards zerowaste concepts in general. Pietzsch et al. (2017) categorizes these contextual factors as barriers in the macro-, meso- and 
microenvironments. Barriers in macroenvironments may include political issues, such as a lack of guidelines, and cultural issues, such as a lack of efficient communication. Further economic challenges in the macro-environment might include a coherent planning of taxation and uncertain market dynamics, while also technological aspects like the need for research and investments for innovative waste management technologies come into play. The biggest issues Pietzsch et al. (2017) identify on a meso- and microlevel are the lack of knowledge and understanding of the zero waste concept and the perception of costs.

Beitzen-Heineke et al. (2017) identify more specific challenges for packaging free stores, in the areas "operations", "logistics", "marketing and sales", "procurement" and "technological development" of the value chain. These challenges derived from expert interviews include inconvenience for consumers who need to plan ahead and have to deal with a smaller variety of products, challenges for stores when choosing suppliers that provide reusable or recyclable packaging, technological challenges for the weighing and paying system as well as food waste, packaging functionality and food safety issues. Similarly, Kröger et al. (2017) present a brief overview of barriers which include difficulties to transform packaging processes, lack of demand of consumers, additional efforts and inconveniences for consumers. These barriers are accompanied by further cultural, social and psychological barriers when adjusting routines and behavioral patterns. Based on conceptual and qualitative research, Smits Sandano (2016) provides a typology of barriers arising for no-packaging stores that also covers the different elements identified by Pietzsch et al. (2017), Beitzen-Heineke et al. (2017) and Kröger et al. (2017). Her analysis was based on a literature review of secondary and primary data and a series of qualitative in-depth interviews with stakeholders from the food retail and packaging industries with the aim of identifying barriers and incentives to zero packaging food retail. Smits Sandano (2016) distinguishes four categories that influence the implementation of the zero waste concept in the food retail industry: regulatory factors, social factors, market factors and resource factors. Regulatory factors mainly describe governmental leadership and the clarity of regulation and legislation and, therefore, apply to the food retail management and are not directly applicable from a consumer perspective. Social factors include aspects such as interest, awareness or perception of convenience, burden or obligation. Market factors comprise the quality and price of the goods, marketing and communications as well as hygiene concerns. Resource factors relate to a firms access, or in case of barriers lack of access, to tangible and intangible resources and the resulting restrictions such as the store location (Smits Sandano 2016).
The above summarized research on contextual barriers specific for the context of purchasing unpackaged food products suggests that these barriers are crucial determinants of an individual's purchasing decisions concerning unpackaged food products. Generally, it can be assumed that the perception of perceived barriers towards a specific behavior, influence whether the respective behavior is implemented. In the context of individual behavior in the domain of leisure time physical activity, Reichert et al. (2007) for example reveal that the perception of barriers influences the likelihood to engage in leisure time physical activity. Likewise, regarding pro-environmental projects concerning supply chain management in organization, Carter and Dresner (2001) assume that if a project was confronted with barriers, it is more likely to fail. Still, they do not find support for this assumption. To test these insights in the context of packaging free purchasing of individuals, we focus on the perception of barriers by an individual and formulate hypothesis 2 as follows:

H2: Consumers who perceive barriers towards purchasing unpackaged food products are less likely to buy unpackaged food products.

In relation to the influence of barriers that can hinder individuals to behave in a pro-environmental manner, Blake (1999) assumes that some of these barriers are less relevant for individuals with high levels of environmental concern. Similarly, many authors argue that specific barriers, such as price concerns are perceived to be less relevant for consumers with high levels of environmental concern. Likewise, Hörisch et al. (2017) argue for the context of proenvironmental entrepreneurial behavior that it is not only the context as such which might influence pro-environmental entrepreneurial behavior, but also the perception of the specific context. Analogously it can be assumed that individuals with high pro-environmental personal norms perceive contextual barriers differently than individuals with less pro-environmental personal norms or even do not perceive some of these barriers at all (cf. Blake 1999). On this basis, hypothesis 3 is formulated:

H3: Consumers with high levels of pro-environmental personal norms perceive barriers towards purchasing unpackaged food products less frequently than consumers with lower levels of pro-environmental personal norms.

Lastly, following the causal steps approach for mediation analyses suggested by Baron and Kenny (1986), hypotheses 1 to 3 logically imply a mediation. More precisely, proenvironmental personal norms influence purchasing of unpackaged food products (hypothesis 1). However, this influence is mediated by the perception of barriers towards such behavior, as the perception of barriers is hypothesized to influence purchasing unpackaged food products (hypothe- 


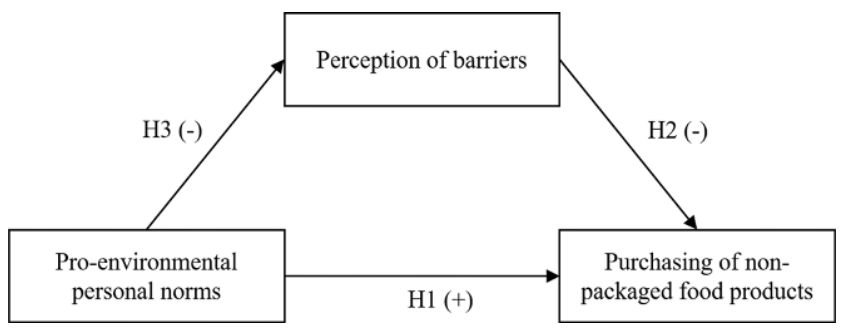

Fig. 1 Summary of hypotheses 1-3 which taken together imply hypothesis 4

sis 2) and in turn pro-environmental personal norms are expected to influence the perception of barriers (hypothesis 3). Consequently, hypothesis 4 is formulated as follows:

H4: The influence of pro-environmental personal norms on purchasing unpackaged food products is mediated by the perception of barriers towards purchasing unpackaged food products.

Fig. 1 summarizes the above described hypotheses. Previous studies additionally document the influence of demographic factors on pro-environmental behavior and purchasing behavior, such as the level of education, household size and gender (e.g. Tanner and Kast 2003). Consequently, these variables were included in the analysis as control variables.

\section{Methods}

A quantitative research approach was chosen to complement previous conceptual and qualitative studies on possible barriers of the implementation of a zero waste strategy in the food retail industry (Smits Sandano 2016; BeitzenHeineke et al. 2017; Kröger et al. 2017). For this purpose, a survey was conducted at a supermarket in a medium-sized German town. The specific supermarket has been chosen, as it includes a packaging free store, run by a legal entity separate from the supermarket, as well as a conventional assortment of packaged goods. The chosen setting provides a specifically relevant sample, as over $80 \%$ of German consumers state their willingness to purchase unpackaged products, however, only $35 \%$ would prefer a purchase in packaging free stores while $63 \%$ prefer a purchase in supermarkets with an unpackaged food department (Beitzen-Heineke et al. 2017). Within the chosen supermarket, no further selection criteria of the respondents were applied. The data collection took place in March 2018, including weekdays and the weekend. Customers at the supermarket were asked to fill out a questionnaire or were alternatively offered to go through the questionnaire by being interviewed. In total 128 customers participated in the survey. Table 1 summarizes the descriptive statistics of the sample.
Table 1 Descriptive statistics of the sample

\begin{tabular}{lll}
\hline & Mean $^{\mathrm{a}}$ & SD \\
\hline 1. Personal norms & 3.76 & 0.938 \\
2. Barriers & 1.18 & 1.121 \\
3. Purchasing behavior & 0.22 & 0.415 \\
4. Gender & 0.39 & 0.490 \\
5. Household size & 2.55 & 1.243 \\
6. Education & 0.41 & 0.494 \\
7. Age & 37.68 & 15.92 \\
\hline
\end{tabular}

${ }^{\mathrm{a}}$ For metric variables the arithmetic mean is displayed. For binary variables the share of individuals characterized by a specific outcome of the variable is displayed (gender: share of males; education: share of individuals holding a university degree)

The measurement of "personal norms" was adapted from Harland et al. (1999) and relates to the specific context of purchasing packaging free food. Respondents were asked to assess the three statements listed in Table 2 on 5-point rating scales ranging from "I don't agree at all" $(=1)$ to "I totally agree" $(=5)$. The reliability of the measurement scale was confirmed, as Cronbach's $\alpha(0.794)$ exceeds the critical value of 0.7 .

To capture potential barriers that hinder or complicate purchases of unpackaged food products, respondents were asked the following open-question: "Which factors impede you personally from purchasing unpackaged food products at [name of the supermarket] or respectively have prevented you so far from purchasing unpackaged food products at [name of the in-store unpackaged food store]?". This format was chosen in order to enable participants to state all possible barriers they perceive and to avoid biasing respondents towards pre-defined barriers. The appendix includes the frequency distribution for the number of barriers stated per respondent. Respondents could also state that they perceived no barriers or could alternatively skip this question (resulting in missing values). If respondent skipped the question on barriers, they were excluded from the respective analysis.

For testing the hypotheses, the dummy variable "barriers" on the perception of barriers towards purchasing unpackaged food products was set up. This variable distinguishes respondents who perceive at least one barrier from respondents not perceiving any barriers towards purchasing unpackaged food products.

The specific answers concerning potential barriers were coded by two independent coders, drawing on the framework provided by Smits Sandano (2016). Based on the four categories "regulatory factors", "social factors", "market factors" and "resource factors", specific barriers mentioned in earlier literature (Beitzen-Heineke et al. 2017; Pietzsch et al. 2017; Kröger et al. 2017) could be extracted. Thus, each specific barrier formed a variable which was then coded as "mentioned" $(=1)$ or "not mentioned" $(=0)$. 
Table 2 Items included in the measurement of pro-environmental personal norms

\begin{tabular}{llll}
\hline Construct & Items & Source & Cronbach's $\alpha$ \\
\hline $\begin{array}{l}\text { Personal } \\
\text { norms }\end{array}$ & I feel a strong personal obligation to reduce the packaging quantities of my purchase & Harland & 0.794 \\
& I am willing to make an extra effort in order to purchase food products unpackaged & & \\
& $\begin{array}{l}\text { I would feel guilty, if I bought a product with packaging if I had the unpackaged alterna- } \\
\text { tive available as well }\end{array}$ & \\
\hline
\end{tabular}

Barriers that were not pre-defined in earlier literature but were mentioned frequently were formed into a new variable in order to have a more specific distinction of newly occurring barriers. Therefore, the new category "Other barriers" was introduced. The reliability of this procedure was confirmed by a Krippendorff's Alpha of 0.791 , thus exceeding the critical value of 0.667 (Krippendorff 2004).

To measure the dependent variable, i.e. purchasing behavior, approaches adapted from studies with similar study goals concerning green food purchases and packaging avoidance were used (Thøgersen 1999; Tanner and Kast 2003). The respondents reported how many of their last five purchases at this supermarket included food products from the unpackaged section. Next, the responses were recoded to a dummy variable on purchasing behavior. Respondents who indicated that 1 to 5 of their last purchases included products from the unpackaged section were coded as "packaging free customers" whereas those who did not purchase unpackaged food products were recoded as "conventional customers". This procedure drawing on an objectifiable measure (i.e. the countable number of purchases at the unpackaged section) was employed, to reduce a potential self-reported bias. An analysis of the actual number of last 5 purchases which included products from the unpackaged section shows that those coded as "packaging free customers" on average purchased products from the unpackaged section in 2.43 of their last 5 purchases.

Last, control variables (gender, education, household size) were surveyed based on established categories gained from the German Federal Office of Statistics (Destatis 2017; Destatis 2018a, 2018b). Education was operationalized as a dummy variable indicating whether or not an individual holds a university degree. The variable "household size" measures the number of individuals living in the same household.

\section{Results}

Overall, the results reveal that $78 \%$ of the surveyed consumers did not purchase products from the unpackaged section of the respective supermarket in at least one of their last 5 purchases. This highlights the importance of identifying barriers that hinder consumers from purchasing unpackaged food products. To do so, first a descriptive analysis was conducted. Based on Smits Sandano (2016) four
Fig. 2 Barriers towards purchasing unpackaged food products. Classification in accordance with Blake (1999)

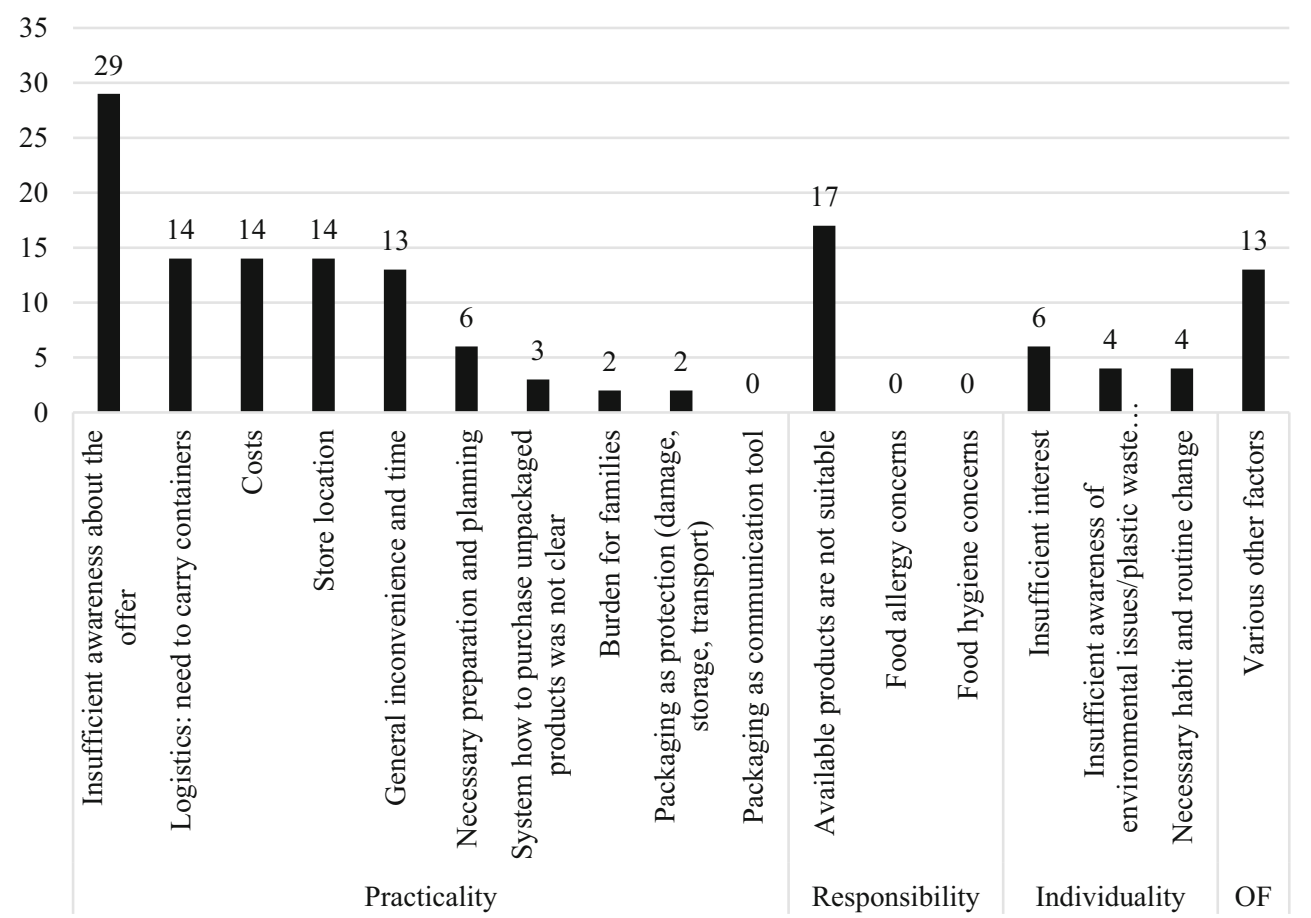


Table 3 Binary logistic and linear regression models

\begin{tabular}{|c|c|c|c|c|}
\hline & $\begin{array}{l}\text { Model } 1 \\
\text { Purchasing behavior }\end{array}$ & $\begin{array}{l}\text { Model } 2 \\
\text { Purchasing behavior }\end{array}$ & $\begin{array}{l}\text { Model } 3 \\
\text { Barriers }\end{array}$ & $\begin{array}{l}\text { Model } 4 \\
\text { Purchasing behavior }\end{array}$ \\
\hline Personal norms & $1.055(0.006)$ & 1 & $0.071(0.774)$ & $1.214(0.003)$ \\
\hline Barriers & l & $-1.513(0.005)$ & l & $-1.743(0.002)$ \\
\hline Education & $1.100(0.027)$ & $1.252(0.014)$ & $-0.199(0.657)$ & $1.258(0.019)$ \\
\hline Household-size & $0.147(0.477)$ & $0.276(0.182)$ & $0.335(0.086)$ & $0.281(0.209)$ \\
\hline Gender (female) & $0.778(0.165)$ & $0.753(0.181)$ & $-1.311(0.010)$ & $0.367(0.542)$ \\
\hline Constant term & $-5.790(0.001)$ & $-2.060(0.011)$ & $0.749(0.490)$ & $-6.548(0.000)$ \\
\hline Model fit (Nagelkerke's $r^{2}$ ) & 0.240 & 0.222 & 0.126 & 0.348 \\
\hline$N$ & 117 & 112 & 112 & 112 \\
\hline
\end{tabular}

Unstandardized regression coefficients are reported. The level of significance is provided in brackets. Significant coefficients $(p<0.05)$ are highlighted in bold

categories of barriers were distinguished, i.e. social factors, market factors, regulatory factors and resource factors. The specific barriers perceived are displayed in Fig. 2. Interestingly, the barriers Smits Sandano (2016) identified in the category "regulatory factors" were not relevant from a consumer perspective. Additional factors that do not belong to any of the categories suggested by Smits Sandano (2016) and that became evident after the coding were categorized as "other factors".

Investigating the frequencies that each barrier was mentioned, highlights that the main barrier towards purchasing unpackaged food was insufficient awareness about the offer, which was mentioned by 29 respondents. Further barriers that were mentioned by at least $10 \%$ of the respondents include that the products available are not suitable from a consumers perspective (17 respondents), the need to carry containers (14), costs (14), the store location (14) as well as general inconvenience and time constraints (13). Interestingly, other potential barriers that were identified in earlier conceptual literature or qualitative studies drawing on expert interviews, were not found to be of relevance, such as food allergy or hygienic concerns or the missing information provided on the packaging (Smits Sandano 2016). When recoding the different barriers according to the general barriers for implementing pro-environmental intentions in practice, as suggested by Blake (1999) a clear dominance of reasons related to practicability becomes observable, whereas the other categories identified by Blake (1999) are only of minor importance, i.e. responsibility and individuality.

To test hypotheses 1 to 4 , four binary logistic regression models were set up, which are summarized in Table 3. Model 1 uses the purchasing behavior dummy as the dependent variable to test hypothesis 1 . Besides proenvironmental personal norms, model 1 includes the control variables education, household size and gender. Overall, the model shows a relatively high model fit (Nagelkerke's $\left.r^{2}=0.240\right)$. As expected, the variable pro-environmental personal norms exerts a significant positive influence on purchasing of unpackaged products. Hence, hypothesis 1 is confirmed. Additionally, the level of education exerts a significant positive influence, suggesting that individuals holding a university degree are more likely to purchase unpackaged products. None of the other control variables show significant effects.

Model 2 tests the influence of the perception of barriers on purchasing behavior (Hypothesis 2) and again shows a relatively high model fit (Nagelkerkes $\mathrm{r}^{2}=0.222$ ). As hypothesized, the variable barriers exerts a significant negative influence on purchasing behavior, indicating that respondents who perceive barriers towards purchasing unpackaged food products are less likely to show respective purchasing behavior. Thus, hypothesis 2 can be confirmed. As in model 1 , the level of education is also found to positively influence purchasing behavior.

Model 3 tests the influence of personal norms on whether an individual perceives barriers towards purchasing unpackaged food products (Hypothesis 3). Compared to the first two models, the model fit is lower (Nagelkerke's $r^{2}=0.126$ ). Additionally, model 3 reveals that pro-environmental personal norms do not exert a significant influence on the perception of barriers towards purchasing unpackaged food products. Hence, hypothesis 3 cannot be confirmed. Of the control variables, only gender shows a significant influence on the dependent variable, indicating that females tend to perceive barriers towards purchasing unpackaged food products less frequently than males.

Last, model 4 includes pro-environmental personal norms as well as the perception of barriers as predictors of purchasing behavior. The value of Nagelkerkes $r^{2}$ (0.348) shows that the model explains a relatively large share of the variance. As expected in hypothesis 1, proenvironmental personal norms significantly influence purchasing behavior. Additionally, the variable on barriers exerts a significant negative influence on purchasing behavior. Still, hypothesis 4 cannot be confirmed based on the mediation test suggested by Baron and Kenny (1986), as the barriers variable is not influence by personal norms 
(model 3). Nevertheless, model 4 confirms the significant influence of education on purchasing behavior already indicated in models 1 and 2 .

\section{Discussion}

\subsection{Discussion of the overall findings and of identified barriers}

Packaging free stores rely on the support of consumers. By making conscious purchasing choices, consumers can contribute to the reduction of negative environmental impacts (Mainieri et al. 1997). While, the result that $22 \%$ of the respondents purchased products from the unpackaged section in at least one of their last 5 purchases, this does not imply that they are all "intensive customers" of the unpackaged food section. As defined by Kröger et al. (2018), this would require purchasing food products to a substantial part from unpackaged food stores or in-store sections. In contrast, those respondents classified as "packaging free customers" on average purchased products from the unpackaged section in only 2.43 of their last 5 purchases, suggesting that most of the packaging free customers belong to the customer groups Kröger et al. (2018) describes as "seldom purchasers" or "new customers".

Additionally to these general insights, this work provides insights on individual and contextual factors that influence unpackaged purchasing. It has been found that the lack of awareness of the existence of the offer and the unsuitability of the product range are the most frequent barriers towards purchasing unpackaged products. The results thus support the findings by Pietzsch et al. (2017) who analyzed barriers towards zero-waste concepts in general (i.e. without a particular emphasis on packaging free stores) and identified a lack of knowledge and understanding of the zero waste concept as key barriers (Pietzsch et al. 2017).

Other barriers identified in this research include impracticality and inconvenience of the purchase as consumers need to plan ahead, carry reusable containers and need more time for the shopping process. In contrast, food hygiene and food allergy concerns seem not to restrain customers to purchase unpackaged food products. Likewise, when compared to earlier research on other aspects of proenvironmental purchasing of food, such as organic certification (Moser 2015) or with studies predicting purchasing behavior of food in general (Gadema and Oglethorpe 2011; Mai and Hoffmann 2012), cost concerns do not seem to be the prime barrier of purchasing packaging free-food.

With regard to factors that promote the purchase of unpackaged food, the present study finds pro-environmental personal norms to be an important predictor, as hypothesized in H1. This finding is in line with earlier research on aspects of pro-environmental purchasing behavior of food other than packaging, which also found that personal norms and an individual's environmental involvement in general are important promoting factors (Harland et al. 1999; Moser 2015; Janssen 2018). Likewise, it shows similarities between the issue of purchasing unpackaged food products and further aspects of sustainable consumption, such as textile consumption, for which research has also identified an individual's values to be of crucial importance (e.g. Jacobs et al. 2018). Similarly, the finding regarding education is in line with earlier research which showed that higher levels of education result in higher levels of knowledge regarding environmental problems (Kollmuss and Agyeman 2002). Yet, other studies found that higher levels of education do not increase the probability of actual pro-environmental behavior (e.g. Tanner and Kast 2003; Mühlthaler and Rademacher 2017).

As hypothesized in $\mathrm{H} 2$, consumers are less likely to purchase unpackaged food products, if they perceive barriers towards this purchasing behavior. Together with the finding concerning $\mathrm{H} 3$, that an individual's level of pro-environmental personal norms does not influence the perception of barriers towards purchasing unpackaged food products, this provides indication that the barriers perceived by consumers are not only a sign of lacking pro-environmental personal norms. Instead, these barriers seem to be material, as they are also perceived by consumers with high levels of pro-environmental personal norms and pose significant obstacles towards purchasing unpackaged food products.

\subsection{Implications for practice}

Based on the results of this research, it is possible to identify potential interventions and specific recommendations for promoting unpackaged purchasing of food products. With regard to such interventions, Steg and Vlek (2009) differentiate informational and structural strategies. Informational strategies pursue the goal of changing perceptions, motivations, knowledge or norms that lead to pro-environmental behavior. In contrast, structural strategies include changes of formal institutions such as laws or the introduction of incentives. Stern (2000) stresses that behavioral change is most likely, if interventions remove important contextual barriers towards a specific pro-environmental behavior. Besides the differentiation between structural and informational interventions, these can be differentiated with regard to the actors responsible for implementation, such as the public sector or retailers.

Concerning possible interventions to be implemented by the public sector, the results of the regression analyses show that promoting pro-environmental personal norms, can help to foster packaging free purchasing behavior. Additionally, many respondents stated that they were not interested or 
concerned enough with the environmental issues concerning plastic waste or that in everyday life they do not have the time or focus to deal with such issues. To tackle this barrier and to promote pro-environmental personal norms, educational campaigns on the consequences of plastic waste for the environment and for human health can be a promising means. This is not only reflected in the finding that individuals with higher levels of pro-environmental personal norms are more likely to purchase unpackaged food products and in the fact that a lack of concern for environmental issues was frequently mentioned as a barrier by customers, but is also reflected in the positive impact of education on purchasing unpackaged products.

Also the cost barrier could be approached by informational interventions of the public sector. Earlier literature emphasized that individuals with high levels of environmental concern or pro-environmental personal norms who recognize the quality of a product, are less price sensitive (Tanner and Kast 2003; Moser 2015). Therefore, informational campaigns could be launched with the aim of raising consumers' levels of pro-environmental personal norms and the aim of convincing them of the quality and the positive environmental impact of the products.

Complementarily, the price barrier could also be approached by retailers using structural interventions. These can include the introduction of special offers and temporary price reductions on unpackaged products. As many respondents stated that they were not aware of the offer to buy unpackaged food products, additionally, an informational strategy by retailers is likely to bear substantial potential. This strategy should comprise in-store marketing, as even customers who visit the respective supermarket were not aware of the offer. Such marketing will be most effective, if it not only increases the awareness about unpackaged food offerings but also explains the concept. To inform and attract new customers beyond the current users of supermarkets offering in-store unpackaged sections, online and offline advertisement specifically focusing on unpackaged food products can be used. With online communication (e.g. via social media) a broader public could be reached, and a younger audience might be attracted. With offline advertisement (e.g. in form of newspaper entries and articles or informational events), less internet-oriented groups can be addressed.

Another frequently perceived barrier towards purchasing unpackaged food products is general inconvenience, including time-constraints, the necessity to plan ahead and to bring own containers. As many respondents mentioned that they simply forgot the containers at home or did spontaneous shopping trips, it might help to provide additional alternative containers for sale. A deposit system for reusable containers could also be implemented for those customers who forgot their containers at home and do not want to pur- chase new ones. Edeka, a German supermarket-chain, introduced a similar system in selected stores in 2018 (Merkur 2018; taz 2018). Its use has however, not yet been evaluated. Besides increasing the share of packaging free customers, interventions aiming at improving the convenience of purchasing packaging free products are also a promising means to increase the intensity of purchasing unpackaged food products. Currently, most packaging free customers seem to be "seldom purchasers" or "new customers", based on the categorization of Kröger et al. (2018). Interventions aiming at increasing convenience should also aim at incentivizing these groups to become more frequent purchasers, labeled as "intensive customers" by Kröger et al. (2018).

Certain barriers are best approached with a combination of informational and structural strategies of retailers (cf. Steg and Vlek 2009). The barrier that available products are not suitable to the needs of consumers can on the one hand be due to the limited product range or on the other hand due to the particularity of unpackaged products. A structural strategy would thus be to expand the product range. Complementarily, an informational strategy could help to explain why certain products are not available. Additionally, the customers could be informed via the website or social media once a (new) product is integrated to the assortment or is back in stock.

\section{Conclusions}

Besides the insights this research offers and the implications it provides for potential interventions, it also comes along with limitations. First, norms, beliefs and attitudes that constitute environmental involvement of an individual may differ across cultures (Park and Ha 2012; Moser 2015). Consequently, the results of this analysis are specific to Germany and are not directly transferrable to other cultures or countries. Likewise, customers of a supermarket which offers an in-store unpackaged food department were purposefully chosen as the population for this survey, as this is the option for purchasing unpackaged food products most German consumers prefer (Beitzen-Heineke et al. 2017). However, this purposeful selection also implies that the results are specific for this particular setting and the respective supermarket. Future research should verify the results of this analysis using larger samples in different settings.

Further limitations and potentials for future research concern the operationalization of the variables in the survey. The moderator variable used captures only whether a respondent perceives barriers towards purchasing unpackaged food products. It thus does not address how strong the respective barriers are perceived to be. Future research should therefore aim at also capturing the perceived strength of bar- 
riers. This research can provide a profound basis for such future inquiries, as it reveals potential barriers. With regard to the dependent variable, this analysis captures whether or not consumers purchased goods from the unpackaged food section in at least one of their last five purchases at the respective supermarket. However, no information was analyzed on the extent of purchases of unpackaged food. Consequently, it remains open for future research to analyze factors and barriers that influence whether consumers tend to purchase all necessary and available products unpackaged or if they only purchase a small share of food products unpackaged.

Furthermore, future conceptual work could try to establish a theoretical model of environmental behavior for the specific aspect of purchasing unpackaged goods. This article has built on an existing theory, which is applicable in numerous different contexts of environmental behavior, i.e. norm-activation theory (Schwartz 1977), and additionally included barriers identified in prior conceptual and qualitative research (e.g. Smits Sandano 2016). While this approach allowed to confirm that personal norms and the perception of barriers are able to explain the purchasing of unpackaged food to a certain degree, a relevant share of the variance remains unexplained. Therefore, models more specific to the context of purchasing unpackaged goods could help to explain a larger share of variance in behavior and to deduce further interventions for encouraging pro-environmental behavior. Concerning interventions, future research should also address the design and application of specific interventions and evaluate the (long-term) effects of these (Steg and Vlek 2009).

Although packaging free stores are unlikely to solve plastic waste problems globally, they bear a substantial potential for reducing the environmental harm generated by the food industry. Together with the future research recommended, this article can help to unleash the potential of unpackaged food stores to reduce environmental pressure caused by plastic packaging in the food industry. It highlights that purchasing unpackaged food products is still a niche phenomenon practiced only by few consumers. Surprisingly, the results reveal that this is even the case in settings where respective offers for consumers exist. To reduce the negative impact food consumption has on the generation of solid waste and on the accumulation of plastic in the ocean, the awareness about unpackaged food offerings as well as the availability as well as the assortments of these offerings need to be expanded.

Acknowledgements We would like to thank the anonymous reviewers for their helpful comments. Additionally, we are greatful to Alexa Böckel and Merle Käberich for their assistance in coding the data.

Funding Open Access funding provided by Projekt DEAL.
Conflict of interest G.H. Marken and J. Hörisch declare that they have no competing interests.

Open Access This article is licensed under a Creative Commons Attribution 4.0 International License, which permits use, sharing, adaptation, distribution and reproduction in any medium or format, as long as you give appropriate credit to the original author(s) and the source, provide a link to the Creative Commons licence, and indicate if changes were made. The images or other third party material in this article are included in the article's Creative Commons licence, unless indicated otherwise in a credit line to the material. If material is not included in the article's Creative Commons licence and your intended use is not permitted by statutory regulation or exceeds the permitted use, you will need to obtain permission directly from the copyright holder. To view a copy of this licence, visit http://creativecommons.org/licenses/by/4. $0 /$.

\section{Appendix}

\section{Frequency distribution of the number of perceived barriers:}

\begin{tabular}{llllllll}
\hline $\begin{array}{l}\text { No. Of } \\
\text { Barriers }\end{array}$ & 0 & 1 & 2 & 3 & 4 & 7 & $\begin{array}{l}\text { Missing } \\
\text { value }\end{array}$ \\
\hline $\begin{array}{l}\text { Frequency } \\
\text { in } \%\end{array}$ & 28.9 & 35.2 & 20.3 & 9.4 & 0.8 & 0.8 & 4.7 \\
\hline
\end{tabular}

\section{References}

Andrady AL (2015) Persistence of plastic litter in the oceans. In: Bergmann M, Gutow L, Klages M (eds) Marine anthropogenic litter. Springer, New York, pp 57-72

Baron RM, Kenny DA (1986) The moderator-mediator variable distinction in social psychological research: Conceptual, strategic, and statistical considerations. Journal of personality and social psychology 51:1173-1182

Bartl A (2014) Moving from recycling to waste prevention: a review of barriers and enables. Waste Manag Res 32:3-18

Beitzen-Heineke EF, Balta-Ozkan N, Reefke H (2017) The prospects of zero-packaging grocery stores to improve the social and environmental impacts of the food supply chain. J Clean Prod 140:1528-1541

Blake J (1999) Overcoming the "value-action gap" in environmental policy: Tensions between national policy and local experience. Local Environ 4:257-278

Carter CR, Dresner M (2001) Purchasing's role in environmental management: cross-functional development of grounded theory. J Supply Chain Manag 37:12-27

Destatis (2017) Statistisches Jahrbuch 2017: Bildung. https://www. destatis.de/DE/Publikationen/StatistischesJahrbuch/Bildung.pdf? _blob=publicationFile. Accessed: 1 May 2018

Destatis (2018a) Einkommen, Einnahmen \& Ausgaben. https://www. destatis.de/DE/ZahlenFakten/GesellschaftStaat/Einkommen KonsumLebensbedingungen/EinkommenEinnahmenAusgaben/ Tabellen/Haushaltsnettoeinkommen.html. Accessed: 1 May 2018

Destatis (2018b) Beruflicher Bildungsabschluss nach Migrationsstatus, Staatsangehörigkeit und Erwerbsstatus. https://www.destatis.de/ DE/ZahlenFakten/GesellschaftStaat/BildungForschungKultur/ 
Bildungsstand/Tabellen/BildungsabschlussBB.html. Accessed: 1 May 2018

European Commission (2018) Proposal for a directive of the European Parliament and of the Council on the reduction of the impact of certain plastic products on the environment. http://ec.europa.eu/ environment/circular-economy/pdf/single-use_plastics_proposal. pdf. Accessed: 1 May 2018

Gadema Z, Oglethorpe D (2011) The use and usefulness of carbon labelling food: a policy perspective from a survey of UK supermarket shoppers. Food Policy 36:815-822

Gardner GT, Stern PC (1996) Environmental problems and human behavior. Allyn \& Bacon, Needham Heights

Goldkorn F, Kröger M, Pape J (2017) Der verpackungsfreie Supermarkt: Wertschöpfungsketten neu denken und Barrieren überwinden. Ökol Wirtsch 32:12-13

Halkos G, Petrou KN (2018) Assessing waste generation efficiency in EU regions towards sustainable environmental policies. Sustain Dev 26:281-301

Harland P, Staats H, Wilke H (1999) Explaining proenvironmental intention and behavior by personal norms and the theory of planned behavior. J Appl Soc Psychol 29:2505-2528

Hörisch J, Kollat J, Brieger SA (2017) What influences environmental entrepreneurship? A multilevel analysis of the determinants of entrepreneurs' environmental orientation. Small Bus Econ 48:47-69

Jacobs K, Petersen L, Hörisch J, Battenfeld D (2018) Green thinking but thoughtless buying? An empirical extension of the value-attitude-behaviour hierarchy in sustainable clothing. J Clean Prod 203:1155-1169

Jambeck JR, Geyer R, Wilcox C, Siegler TR, Perryman M, Andrady AL, Law KL et al (2015) Plastic waste inputs from land into the ocean. Science 347:768-771

Janssen M (2018) Determinants of organic food purchases: evidence from household panel data. Food Qual Prefer 68:19-28

Jurgilevich A, Birge T, Kentala-Lehtonen J, Korhonen-Kurki K, Pietikäinen J, Saikku L, Schösler H (2016) Transition towards circular economy in the food system. Sustainability 8:1-14

King AM, Burgess SC, Ijomah W, McMahon CA (2006) Reducing waste: repair, recondition, remanufacture or recycle? Sustain Dev 14:257-267

Kollmuss A, Agyeman J (2002) Mind the gap: why do people act environmentally friendly and what are barriers to pro-environmental behavior? Environ Educ Res 8:239-260

Krippendorff K (2004) Content analysis: an introduction to its methodology. SAGE, Thousand Oaks

Kröger M, Goldkorn F, Pape J (2017) Die Wertschöpfungskette unverpackter Lebensmittel Perspektiven und Herausforderungen: Der verpackungsfreie Supermarkt. In: Wolfrum S, Heuwinkel H, Reents HJ, Wiesinger K, Hülsbergen KJ (eds) Ökologischen Landbau weiterdenken - Verantwortung übernehmen - Vertrauen stärken Freising-Weihenstephan, 7.-10. März 2017. Beiträge der 14. Wissenschaftstagung Ökologischer Landbau. Verlag Dr. Köster, Berlin, pp 680-683

Kröger M, Wittwer A, Pape J (2018) Unverpackt einkaufen: Mit neuen Routinen aus der Nische? Ökol Wirtsch 33:46-50

Mai R, Hoffmann S (2012) Taste lovers versus nutrition factseekers: how health consciousness and self-efficacy determine the way consumers choose food products. J Consum Behav 11:316-328
Mainieri T, Barnett E, Valdero T, Unipan JB, Oskamp S (1997) Green buying: the influence of environmental concern on consumer behavior. J Soc Psychol 137:189-204

Marsh K, Bugusu B (2007) Food packaging: roles, materials and environmental issues. J Food Sci 72:39-55

Merkur (2018) Edeka führt Dosen an Wursttheke ein - nicht alle Kunden sind zufrieden (15.10.2018). https://www.merkur.de/ wirtschaft/edeka-fuehrt-dosen-an-wursttheke-ein-nicht-allekunden-sind-zufrieden-zr-10079456.html. Accessed 18 Jan 2019

Moser AK (2015) Thinking green, buying green? Drivers of pro-environmental purchasing behavior. J Consum Mark 32:167-175

Mühlthaler T, Rademacher L (2017) The empowered consumer. Sustain Manag Forum 25:189-202

Park J, Ha S (2012) Understanding pro-environmental behavior: A comparison of sustainable consumers and apathetic consumers. Int Manag Retail Distrib Manag 40:388-403

Pietzsch N, Ribeiro JLD, de Medeiros JF (2017) Benefits, challenges and critical factors of success for zero waste: a systematic literature review. Waste Manag 67:324-353

Reichert FF, Barros AJD, Domingues MR, Hallal PC (2007) The role of perceived personal barriers to engagement in leisure-time physical activity. Am J Public Health 97:515-519

Schwartz SH (1977) Normative influences on altruism. Adv Exp Soc Psychol 10:221-279

Sjölund V (2016) Zero Waste within the food sector and an evaluation of the package-free distribution of two different food products: The environmental impact of different packaging models of oats and rapeseed oil: a case study of a Danish package-free retail store compared to a reference, packaged scenario. Department of Design Sciences, Faculty of Engineering LTH, Lund University, Lund

Smits Sandano A (2016) Barriers and incentives to zero packaging food retail: a global stocktake. International Institute for Industrial Economics, Lund University, Lund

Steg L, Vlek C (2009) Encouraging pro-environmental behavior: an integrative review and research agenda. J Environ Psychol 29:309-317

Stern PC (2000) Toward a coherent theory of environmentally significant behavior. J Soc Issues 56:407-424

Tanner C, Kast SW (2003) Promoting sustainable consumption: determinants of green purchases by Swiss consumers. Psychol Mark 20:883-902

TAZ (2018) Eine Mehrwegdose für die Wursttheke (02.08.2018). http://www.taz.de/!5525888/. Accessed 18 Jan 2019

Thøgersen J (1999) The ethical consumer: moral norms and packaging choice. J Consum Policy 22:439-460

Williams H, Wikström F, Otterbring T, Löfgren M, Gustafsson A (2012) Reasons for household food waste with special attention to packaging. J Clean Prod 24:141-148

Zaman AU (2016) A comprehensive study of the environmental and economic benefits of resource recovery from global waste management systems. J Clean Prod 124:41-50

Zeiss R (2018) From environmental awareness to sustainable practices: a case of packaging-free shopping. In: Dhiman S, Marques J (eds) Handbook of engaged sustainability. Springer, Cham, pp 729-754 